\title{
Bombacaceae endémicas del Perú
}

\section{Blanca León ${ }^{1,2}$}

${ }^{1}$ Museo de Historia Natural, Av. Arenales 1256, Aptdo. 14-0434, Lima 14, Perú

2 Plant Resources Center, University of Texas at Austin, Austin TX 78712 EE.UU.

blanca.leon@mail.utexas.edu

\section{Resumen}

En este trabajo, la familia Bombacaceae es considerada aparte de las Malvaceae, con la cual se considera forma un grupo natural (ver Judd et al. 1997 y la página de internet de Angiosperm Phylogeny Group). En el Perú, las Bombacaceae incluyen 15 géneros y 56 especies (Brako \& Zarucchi, 1993; Ulloa Ulloa et al., 2004), generalmente árboles. Siete especies en cinco géneros son endemismos del país. Estas especies endémicas ocupan principalmente las regiones Bosques Secos y Bosques Húmedos Amazónicos, entre los 1300 y 3000 m de altitud. Se aplicaron las categorías y criterios de la UICN a cuatro especies. Ninguna de las Bombacaceae endémicas está representada en el Sistema Nacional de Áreas Naturales Protegidas por el Estado.

Palabras claves: Bombacaceae, Malvaceae, Perú, endemismo, plantas endémicas.

\section{Abstract}

The Bombacaceae are recognized here as distinct from the Malvaceae, with which it forms a natural group (see Judd et al. 1997, and web site of the Angiosperm Phylogeny Group). In Peru, the Bombacaceae include 15 genera and 56 species (Brako \& Zarucchi, 1993; Ulloa Ulloa et al., 2004), mostly trees. Seven endemic species in five genera are recognized here. Endemic species are found mainly in Dry Forests and Humid Lowland Amazonian Forests regions, between 1300 and 3000 m elevation. We applied IUCN categories and criteria to four of them. None of the species have been recorded to date within Peru's protected areas system.

Keywords: Bombacaceae, Malvaceae, Peru, endemism, endemic plants.

\section{Ceiba mythica Ravenna}

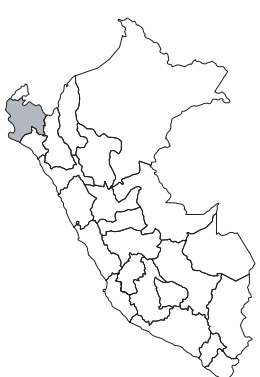

\section{NE}

Publicación: Onira 3(15): 47. 1998.

Colección tipo: P.F. Ravenna 2570

Herbarios: Hb. Ravenna.

Nombre común: Desconocido

Registro departamental: PI.

Regiones Ecológicas: BS; 2400—2600 m. SINANPE: Sin registro.

Herbarios peruanos: Ninguno.

Observaciones: Esta especie se conoce solamente de una localidad en el norte del país, en la cuenca del río Huancabamba. No hay información adicional sobre el estatus taxonómico de esta especie.

\section{Eriotheca peruviana A. Robyns

$$
\text { CR, B1ab(iii) }
$$

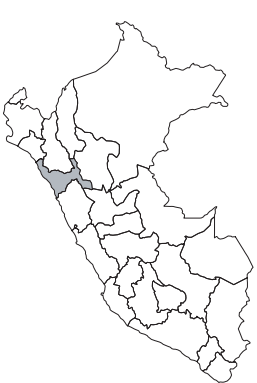

Publicación: Ann. Missouri Bot. Gard. 55(1): 51, f. 1. 1968.

Colección tipo: P.C. Hutchison et al. 6228

Herbarios: UC, US.

Nombre común: Desconocido.

Registro departamental: LL.

Regiones Ecológicas: BS; $1300 \mathrm{~m}$.

SINANPE: Sin registro.

Herbarios peruanos: HUT (1).

Observaciones: Esta especie arbórea se conoce solamente de poblaciones en el cañón del río Marañón. Aparentemente no ha vuelto a ser recolectada desde la década de 1960.

\section{Eriotheca vargasii A. Robyns}

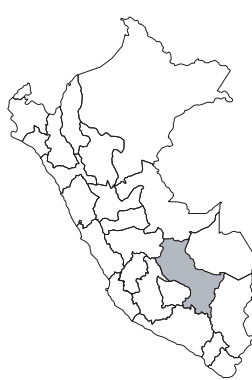

\section{$\mathrm{NE}$}

Publicación: Bull. Jard. Bot. Etat 33(2): 165-166. 1963.

Colección tipo: C. Vargas C. 1087

Herbarios: $F$

Nombre común: Desconocido.

Registro departamental: CU.

Regiones Ecológicas: BS; altitud desconocida.

SINANPE: Sin registro.

Herbarios peruanos: Ninguno.

Observaciones: Árbol conocido sólo del sur del país, probablemente de los fragmentos de bosque seco. Aparentemente no ha vuelto a ser recolectada desde 1938.

\section{Matisia longitubulosa (A. Robyns) Cuatrec.}

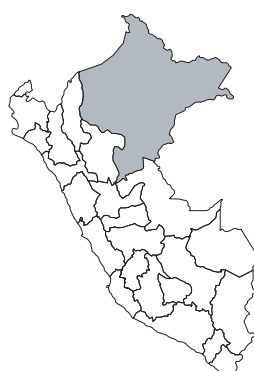

\section{DD}

Publicación: Phytologia 20(8): 471. 1971.

Colección tipo: J.J. Wurdack 2102

Herbarios: F, NY, UC, US; USM!.

Nombre común: Desconocido.

Registro departamental: LO.

Regiones Ecológicas: BHA; 250-300 m.

SINANPE: Sin registro.

Herbarios peruanos: USM (isotipo).

Observaciones: Árbol conocido de la cuenca del Marañón, de una sola colección realizada en 1962. Esta especie parece estar limitada a bosques no inundables. 


\section{Pseudobombax cajamarcanus Fern. Alonso}

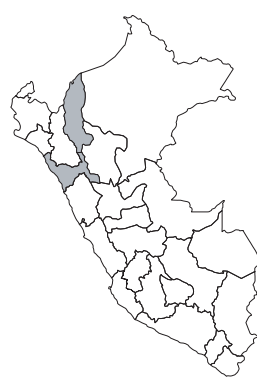

\section{EN, B1a}

Publicación: Revista Acad. Colomb. Ci. Exact. 9 25(97): 468, f. 1a-b. 2001.

Colección tipo: C. Díaz 2189

Herbarios: COL, MO; USM!

Nombre común: Baldaco, choccllo. Registro departamental: AM, LL.

Regiones Ecológicas: BS; 1550—3000 m.

SINANPE: Sin registro.

Herbarios peruanos: USM (isotipo).

Observaciones: Esta especie arbórea es conocida solamente de la cuenca del río Marañón. La localidad original, que fue reconocida erróneamente como de Cajamarca, está muy cerca de la conocida para otra endémica, Eriotheca perwviana. Al parecer, está restringida a esta cuenca, necesitándose conocer el tamaño de sus poblaciones y las amenazas que soporta.

\section{Quararibea bilobata A. Robyns}

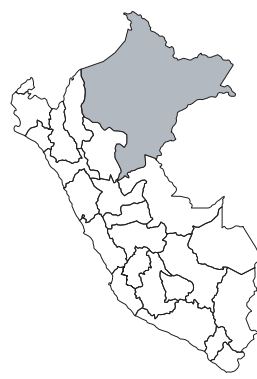

Publicación: Ann. Missouri Bot. Gard. 55(1): 54-55, f. 2. 1968.

Colección tipo: J.J. Wurdack 2450

Herbarios: NY, UC, US; USM!.

Nombre común: Desconocido.

Registro departamental: LO.

Regiones Ecológicas: BHA; 200—250 m.

SINANPE: Sin registro.

Herbarios peruanos: USM (isotipo).

Observaciones: Esta especie tiene vínculos con Quararibaea amazonica de Brasil. Se conoce, al parecer, de una localidad, en el occidente del Departamento de Loreto, en la cuenca del Marañón. No ha sido posible evaluarla, ni asignarle una categoría.

\section{Quararibea velutina Cuatrec.}

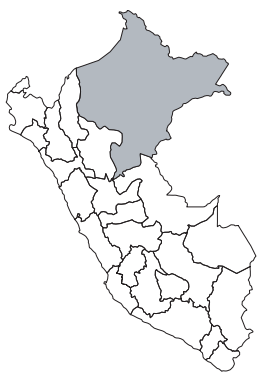

Publicación: Phytologia 4(8): 475. 1954. Colección tipo: J.M. Schunke 235

Herbarios: F, US.

Nombre común: Machinnaccha.

Registro departamental: LO.

Regiones Ecológicas: BHA; 100-125 m.

SINANPE: Sin registro.

Herbarios peruanos: Ninguno.

Observaciones: Esta especie arbórea se conoce solamente de una localidad en la cuenca del río Mazán y al parecer, no ha vuelto a ser recolectada desde 1920. No ha sido posible evaluarla, ni asignarle una categoría. 